\title{
Review of: "The effect of different government subsidies on total-factor productivity: Evidence from private listed manufacturing enterprises in China"
}

\author{
Desheng $\mathrm{Wu}^{1}$ \\ 1 China University of Geosciences Wuhan
}

Potential competing interests: The author(s) declared that no potential competing interests exist.

The author mainly wants to explore the productivity effect of subsidies by studying different types of subsidies. The topic is interesting, but the publication of this article requires further answers to the following questions: (1) The marginal contribution of the paper is insufficient, especially for the second and third point. Heterogeneity discussion and data of listed private enterprises seem to be difficult to prove the author's innovation, and a large number of literatures have adopted similar practices. (2) Following the first point, the first point seems interesting, but the introduction can further explain why the two types of subsidies are focused on $R \& D$ and production. $\square 3 \square$ Whether mechanism analysis can refine more targeted channels, financing and innovation seem to become stylized mechanisms (4) In the part of mechanism testing, it is necessary to explain further the methods and reasons for selection (5) In the policy suggestion part, it seems that similar suggestions can be obtained without research, and targeted measures need to be supplemented (6) The article mentioned that the use of listed company database may cause errors, why not choose the industrial enterprise database in advance? Such databases are open access and are widely used in related topics in this article $77 \square$ Need to further improve the logic and refinement of the language 